\title{
Determination of Effective Policies for Ecological Agriculture Development with System Dynamics and Agent Based Models - Case Study in Slovenia
}

\author{
Črtomir Rozman, Andrej Škraba, Karmen Pažek, \\ Miroljub Kljajić, Martina Bavec and Franci Bavec \\ Univeristy of Maribor/Faculty of Agriculture and Life Sciences \\ Univeristy of Maribor/Faculty of Organizational Sciences \\ Slovenia
}

\section{Introduction}

Agricultural activity, beyond its primary function, can also shape the landscape, provide environmental benefits such as land conservation, sustainable management of renewable natural resources and preservation of biodiversity, and contribute to the socioeconomic viability of many rural areas (Majkovič et al., 2005). One way of emulating the prevailing EU policy reform trends is also to support and encourage organic farming, which is gaining in importance in Slovene agricultural production. Contemplated as a whole, any sound agricultural reform would entail not only necessary positive shifts in economic efficiency levels concerning the production and processing of food, but should specifically address some key socio-economic issues that are at the core of preserving and maintaining the ecological balances in the Slovene countryside; with biodiversity becoming an increasingly important agricultural policy concern (Ivančič et al., 2003). With respect to terms of multifunctionality, organic agriculture is the highest environmentally valuable agricultural system (Rozman et al., 2007a, 2007), and has strategic importance at national level that goes beyond the interests of agricultural sector.

This alternative agricultural paradigm may provide the link between objectives of sustainable resource use and sustainable regional development. The consequences of policies are long term and irreversible. In this light the conceptual methodological approach for evaluation of development policies for organic farming must be developed. Organic agriculture represents a complex system at national level (Shi and Gill, 2005) and different modeling approaches have been described in the literature (farm level, regional level and national level). Also, technologic economic simulation at farm level and multicriteria decision analysis are often used for decision support at farm level (Rozman et al, 2005; Pažek et al, 2006). Boorsma (1990) distinguishes three approaches in modelling the behaviour of the farmer: econometric modelling (based on linear regression equations of a data set); mathematical programming and modelling decision processes based on decision rules. At the national and regional level we often encounter econometric models that can 
efficiently reflect the situation in agricultural systems and can also be used for forecasting policy consequences (Akinwumi et al., 2000, Turk (1998)). Although econometric models have a great methodological value and forecasting capabilities the modeler must ensure relatively long and consistent data series that are rarely available. Mathematical programming is frequently applied in farm planning. It allows determination of an optimal allocation of land, labour and capital, given a set of goals (e.g. maximisation of income and leisure and minimisation of risk) and constraints (e.g. labour and land). Boutkes and Van Keuler (2003) argue that the study of agricultural systems requires the use of non-linear dynamic models that allow simulation of the system in a qualitative way, based on a description of the underlying processes. Their approach is illustrated with a regional model that has been developed to simulate agricultural development in the Koutiala region in the south-western part of Mali. There are many factors, such as farm type and soil quality, that might influence farmers' decisions. However, attempting to consider the complex interactions of all factors in a single model is not a productive approach. Hence, the authors (Kaufmann et al., 2009) adopted the approach of isolating parts of a system and examining it assuming that all other things are equal. The diffusion of organic farming practices is modeled by a generic agent model (Borchev and Filippov, 2004) based on Theory of planned behavior for understanding and modeling the farmers decision making process.

System dynamics (SD) methodology (Forrester, 1961) can be and has been used as an alternative to econometric and mathematical programming approaches (Bockerman et al (2005)); Elshorbagy et al (2005)). SD model in its essence, is a continuous model because it is presented as a system of non-linear differential equations (Munitič and Trosić, 1997). There have been many important SD applications in the field of agriculture recentlyShen et al. (2009) present system dynamics model for the sustainable land use and urban development in Hong Kong. The model is used to test the outcomes of development policy scenarios and make forecasts. It consists of five sub-systems including population, economy, housing, transport and urban/developed land. Similar approach is presented by Weber et al. (1996).

However, the most important work in the field of simulation of development policy scenarios are presented by Shi and Gill (2005) who developed a system dynamics based simulation model for ecological agriculture development for Jinshan County (China) and Kljajić et al. (2000, 2001, 2002, 2003) with an integrated system dynamics model for development of Canary Islands where main interactions between agriculture, population, industry and ecology were taken into consideration. The preliminary results of SD simulation of organic farming development is conducted by Rozman et al. (2007) and Škraba et al. (2008). The model incorporates key variables affecting the organic farming systems and is used in identification in of main reasons that the strategic ( $15 \%$ or organic farms) has not been achieved. Yet this research did not incorporate the full aspects of food market and consumer factor (Rozman et al., 2007). However, consumer concerns are inherently dynamic because they respond to difficult and complex societal and technological situations and developments. For example, because of the rising concern with global warming, carbon dioxide absorption of crops is now attracting public attention, which means that new requirements are being proposed for the environmentally friendly production of crops (Korthals, 2008). In this light Rozman et al. (2008) and Rozman et al. (2010) upgraded the model with the inclusion of organic market development factor. 
This paper presents a system dynamics model for development of organic agriculture in Slovenia in order to identify key reasons and propose development policy to achieve strategic goals set in the ANEK (Majcen and Jurcan, 2006). The paper is organized as follows: first we present the state of the art of organic agriculture with its system analysis and identify key variables, main flows and feedback loops in the systems. The results section presents scenarios (different policies in organic farming) and their evaluation using the developed SD model. Main findings and suggestions for further study conclude this article.

\section{Model development}

\subsection{Study area}

We selected the Republic Slovenia as study area in order to develop and employ the SD model. The most of Slovenia agriculture is located (with exception of eastern flat land with its intensive field crop production) in hilly unfavorable areas. In the European space Slovenia belongs to the countries with the most unfavorable conditions because of its diverse and mountainous relief and high proportion of carst areas. Recent studies have also shown deficiencies of organic products on the market (Pažek at al., 2006). Thus organic agriculture has been identified as one of developmental opportunities.

There are approximately 80,000 farms in Slovenia; conventional and organic. In year 2006 only 1,728 farms are in the organic farm control system. Even though the subsidy has been offered (Recent research has shown (Rozman et al., 2007) that correlation between subsidies level and number of organic is too low) to the farmers, the proportion of the organic farms is still low, not higher than $5 \%$. The short term strategic goal is to reach the $10 \%$ or $15 \%$ ratio by the year 2015. This is determined by the state action plan ANEK (Majcen and Jurcan, 2006). Although the number has increased to 2000 in 2007 and 2067 in 2008 the strategic goal $(15 \%)$ is still underachieved.

In Slovenia up to 440,349 hectares are defined as less favoured areas (LFA). These are hilly and mountainous areas, areas with karst features or other factors that limit possibilities of intensive farming. Relatively high share of less favourable areas make Slovenia suitable for less intensive sustainable production systems - such as organic agriculture.

The system analysis of organic agriculture

In order to provide the proper systemic solution of the described problem, the simulation model should be build which represents the structure with key elements. The simulation model should consider the key variables that influence the development of the organic farming such as:

- $\quad$ number of conventional farms

- number of organic farms

- conversion

- $\quad$ subsidies

- promotion of organic farming (marketing, market development, education

- $\quad$ organization of general organic farming support environment

- $\quad$ system self awareness

- delay constants of process changes

The key variable in the model is the number of organic farms. These are the farms that are in the control system at the one of the control organizations. The growth of the number of organic farms was initially (in year 1998) almost linear however, in the years from 2003-2005 the growth is moderated to approximately $4 \%$ despite the increase of subsidies for $20 \%-30 \%$. 


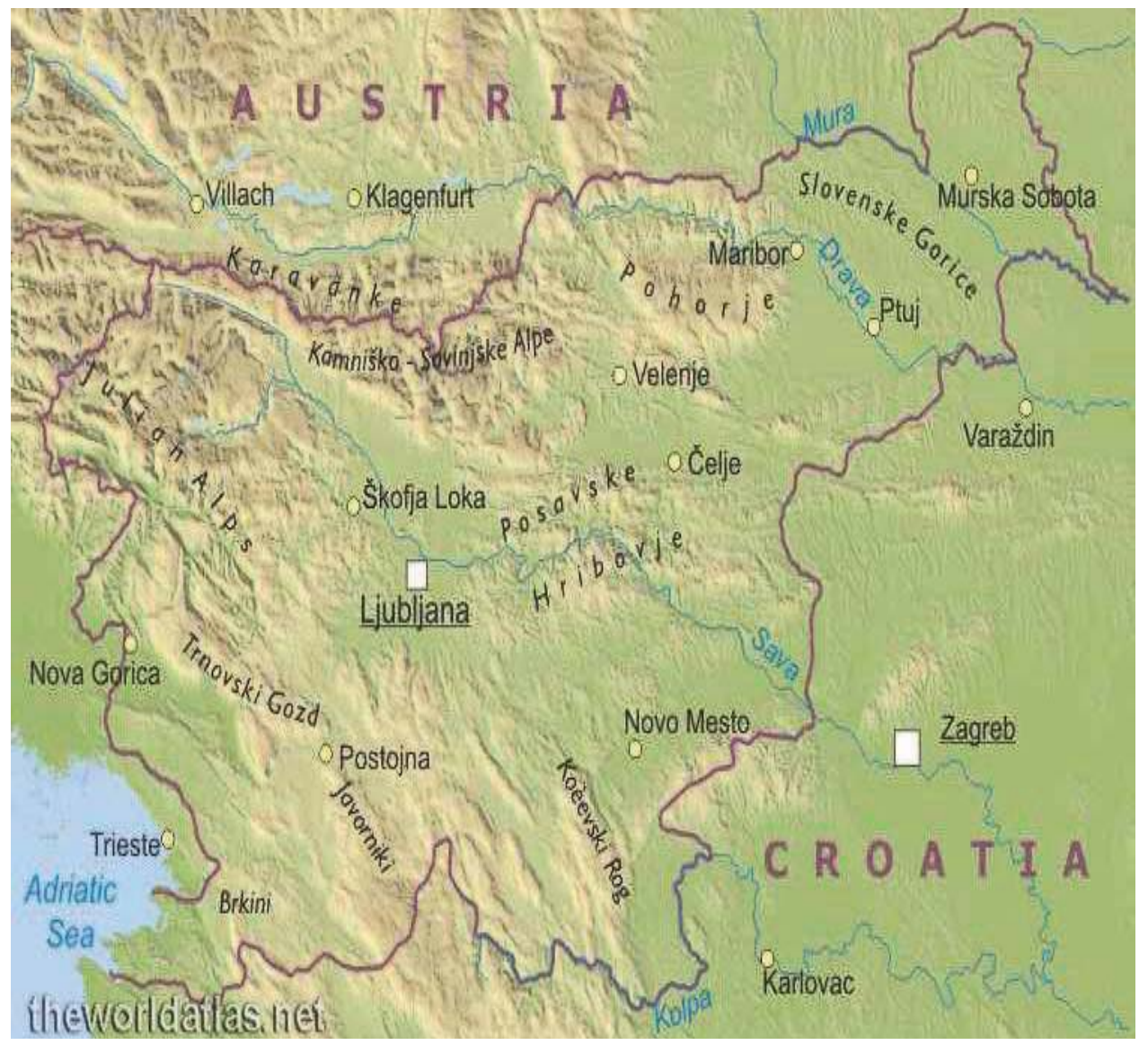

Fig. 1. Map of Republic of Slovenia (relief)

At the development of the causal loop diagram (Fig. 2.) as the first step of the development of SD model the following key variables were identified:

1. the number of potential candidates (farms) for conversion to organic farming

2. the number of farms converted to organic farming

3. the flow between (1) and (2): conversion rate (transition)

Loop (A) represent negative loop with the goal value of 0 (depleting the number of "Conventional Farms"). Number of "Conventional Farms" divided by the "Total Number of Farms" yields the "Concentration of Conventional Farms" which is initially high meaning that there should be high initial preference for "Conversion". "Concentration of Conventional Farms" therefore positively influences the "Communication". This variable represents the general communication between the conventional approach members and organic approach members. "Conversion" positively influences on the number of "Organic Farms". If the number of "Organic Farms" increases, the "Information Spread" increases above the level that would otherwise have been. "Information Spread" by "Organic Farms" member is positively influenced by the "Information Spread Factor" which could be for 
example increased by the marketing campaigns. "Information Spread" positively influences on the "Communication". The number of "Conversion" is determined by the "Success Factor" which determines the "Communication Success" yielding the number of convinced conventional members that decide to make a "Conversion". Loop (B) is reinforcing feedback loop compensated by the initial balancing feedback loop marked with (A). If the number of "Organic Farms" increases, the "Promotion and Marked Development" supported by the "Policy Support Factor" increases above the level that would otherwise have been. Higher "Promotion and Market Development" positively influences the "Self Organization Resources", which positively contribute to the "Support Resources" on which the "Conversion" is dependent on.

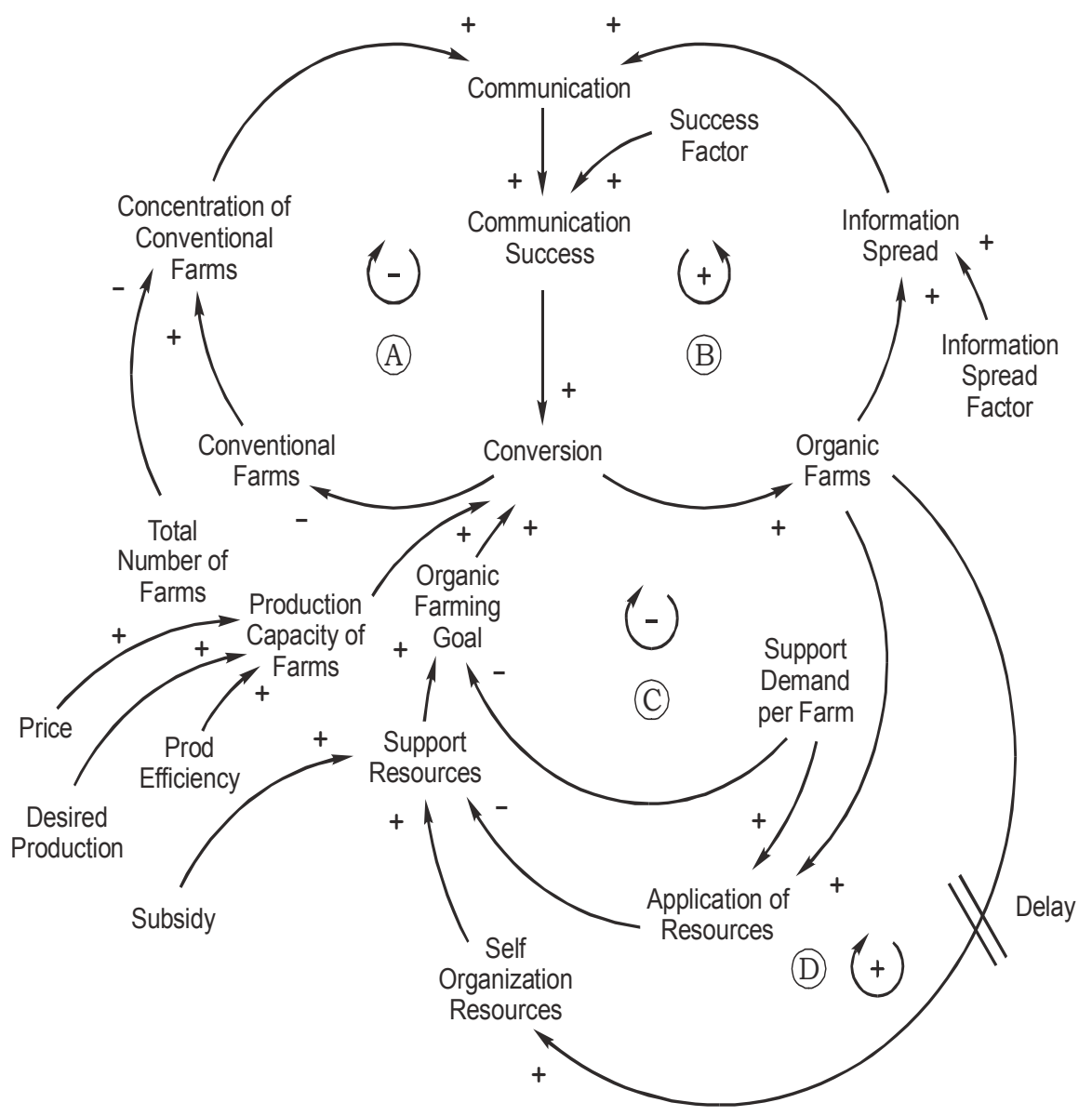

Fig. 2. Causal Loop Diagram (CLD) of system structure

There is the delay mark between the "Promotion and Market Development" and "Self Organization Resources". Here the longer delays should be considered since there is a significant amount of time needed in order to promote the organic farming idea and 
marketing channels which would support the organic farming. "Support Resources" are significantly depended on the government "Subsidy". More there are "Support Resources" higher the "Organic Farming Goal" is set meaning, that larger number of organic farms could be supported. If the "Organic Farming Goal" increases, the "Conversion" increases above the level that would otherwise have been.

Mentioned interconnections marked with (D) has a characteristic of reinforcing feedback loop. By proper government policy the growth in the number of "Organic Farms" should be properly supported in order to promote increase in self organization of e.g. organic food marketing and promotion.

Therefore the reinforcing feedback loop (D) should be applied as the growth generator in the system.

Loop (C) represent balancing loop. If the number of "Organic Farms" increases, the "Application of Resources" increases above the level that would otherwise have been. "Application of Resources" is also dependant on the resources needed per farm i.e. "Support Demand per Farm". Higher "Application of Resources" cause the depletion of the "Support Resources". "Organic Farming Goal" is dependant on the "Support Demand per Farm". If there is more resources needed per farm less organic farms could be supported therefore lower number of "Conversion" could be expected in such case. In considered real case, the negative loops (A) and (C) are dominant leaving the system in unwanted equilibrium state. This would mean, that the number of organic farms is constant well below desired. In order to move the system from the equilibrium one should consider the policies which would raise the impact of reinforcing feedback loops (B) and (D) which should move the system state i.e. number of "Organic Farms" to the higher equilibrium values. Price, Desired production and Production efficiency are also important factors that impact the transition intensity.

Model development

System dynamics model structure is shown in figure 3. Model consists of 29 variables and 51 links.

There are two level elements applied in the upper part of the model. The variable "conventional_farms" represent the number of conventional farms. By the flow "transition" the "conventional_farms" become "organic_farms". This structure is commonly known as the market absorption model. "conversion" is dependent on the "organic_farming_goal". The goal is set by the "support_resources" available modeled as a level element. The conversion could only be achieved if there is enough "support_resoureces" present in order to make a "conversion". The "support_resoures" are not only the financial means. Here the society support is also considered, for example education should provide positive thinking when organic farming is considered. In this category the market development as well as the demand should also be considered. However at present the "support_resources" are mainly dependent on the subsidies form the government. Important variable "self_organization_resources" is driven by the impact of the policy and society support which intensifies with the number of "organic_farms". This represents the application of reinforcing feedback loop which should be augmented. "development_limit" represents the function which consider variable consumption of the resources. If the resources are scarce the usage is lower than in the case of abundance. Resources are consumed by the 
"organic_farms". The prosperity of the "organic farms" therefore depends on the "support_resources" which are not only financial means; here the social impact of organic farming represents the supportive environment which should sustain such an activity which is in the world of consumption counterintuitive (Forrester, 1961).

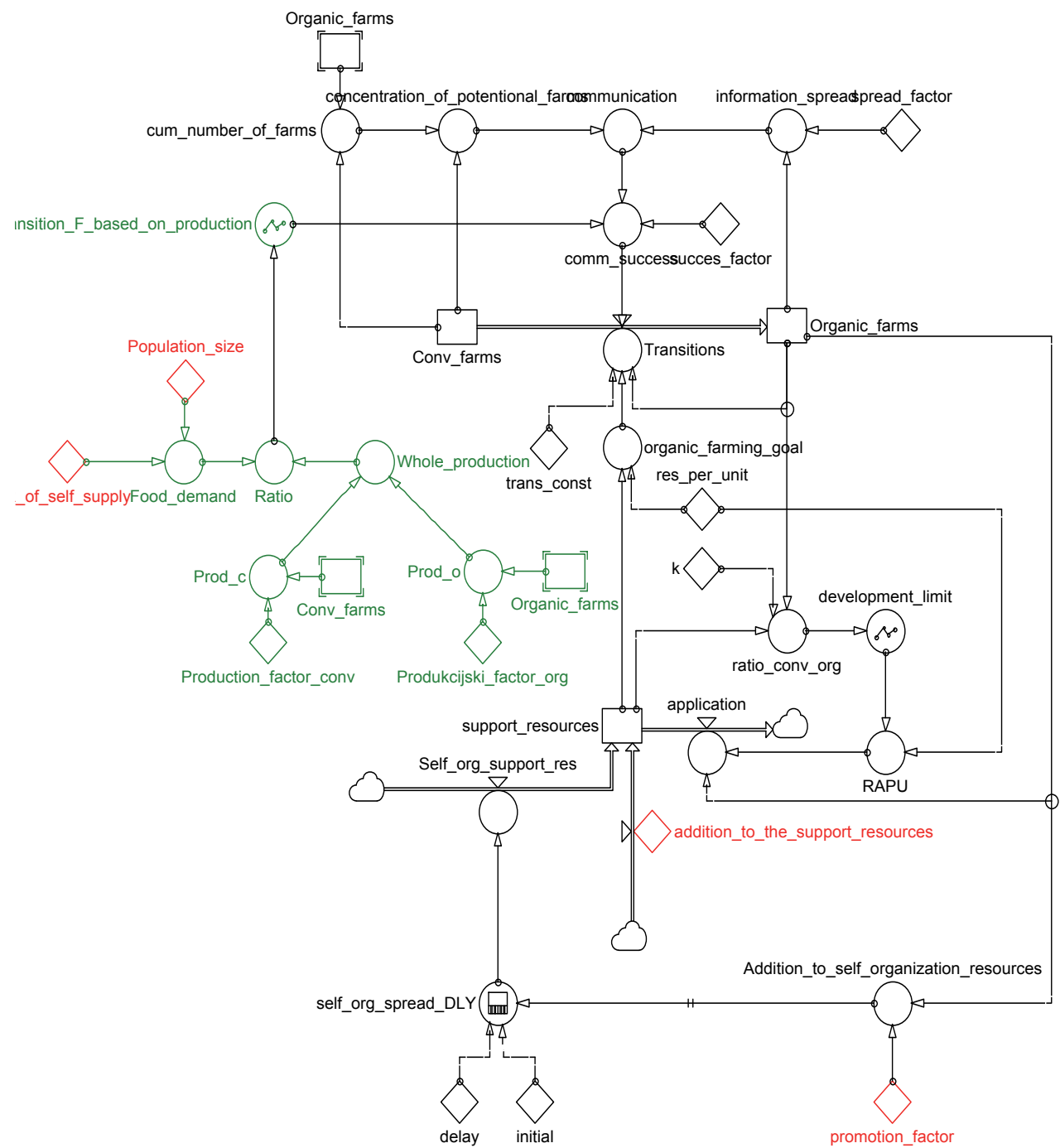

Fig. 3. System Dynamics model of Organic Farming Development

Figure 4 shows model examples of model equations. There are 77,000 conventional farms initially and 1,728 organic farms. The model is realized in Powersim. By the following equations the model could easily be transformed to other SD tools such as Vensim, iThink, Stella etc. 


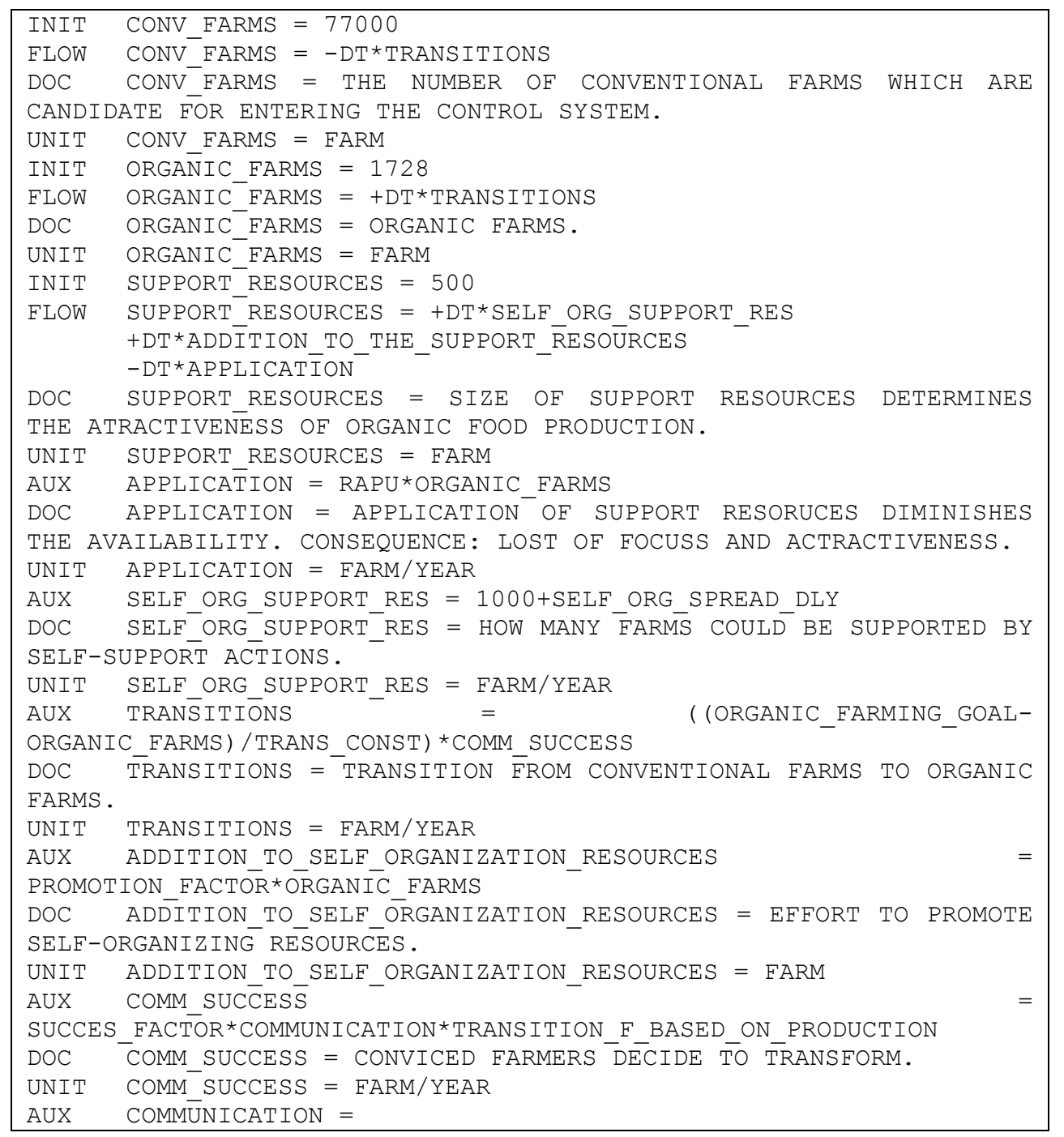

Fig. 4. Examples of model equations

Agent-based approach

In our research the agent-based approach has been considered as the possible way to analyze the dynamics of transition to organic farming. By this, one could compare both methodologies, System Dynamics and Agent-Based modeling. In Agent based model built with AnyLogic (Borschev and Filippov, 2004) shown in figure 4; we define the agents as farms. The model is represented by two agent states; 1) Conventional Farms (red) and 2) Organic farms (green). Transition among particular states is determined by the promotion of organic farming and information spread. The contacts in the state of organic farming is also 
considered. This approach is promising since it is possible to model whole agricultural sector where each particular farm is taken into account. Initially one initializes the particular number of agents, in our case 2000, since this is the number of potential farms for transition. The model is based on the Bass diffusion agent-based model. The number of farms is set to 2000 since the agent model with 20.000 farms would take too much time to run. Initially all the agents are painted red since all the farms are conventional. During the simulation agents transform from conventional to organic farms, which could be observed on the graphical view; the agent turns from red to green. Since the agents could transform from conventional farms to ecological in two ways there are two different border representations. If the agent performs transition on account of the promotion, the border of the agent turns yellow. If agent performs transition on account of other causes, the border turns blue. In this manner one could easily estimate how many agents performed transition in particular was as well as how fast particular transition occurred during simulation.

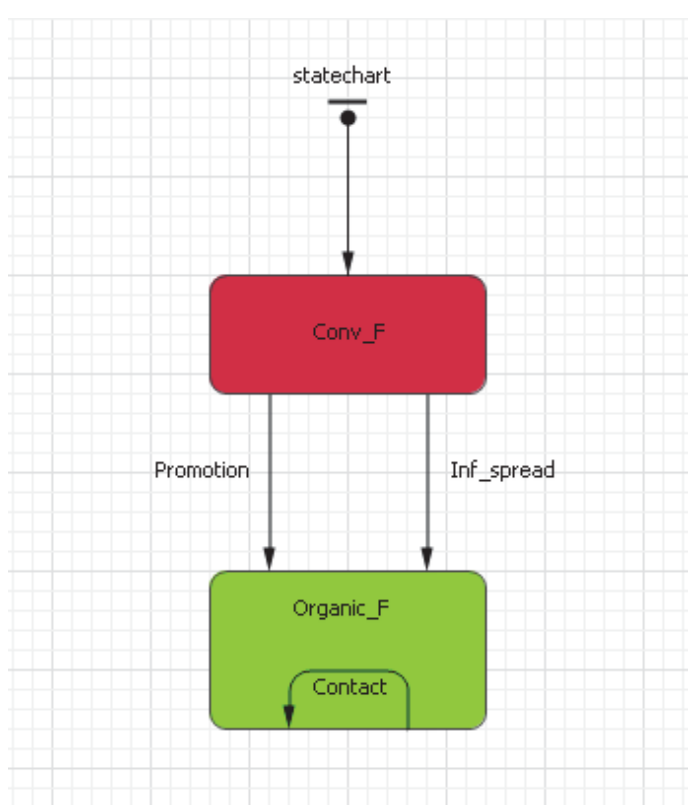

Fig. 5. Agent-based simulation model of transition to organic farming

\section{Results}

Table 1 shows the parameter values for the eight scenarios performed on the developed system dynamics model. SC1 is the initial scenario where the initial amount of the subsidy is provided (1000). This would mean that there are some resources provided by subsidy to support 1000 organic farms.

Figure 5 shows results of eight different simulation scenarios. One of more important findings is, that the system is sensitive to the changes in demand. If one observe scenario 7 and 8 , where the population is changed only for $50 \mathrm{k}$ and $100 \mathrm{k}$, once could observe, that the conversion to the organic farming would be jeopardized. 


\begin{tabular}{|l|l|l|l|l|l|}
\hline Scenario & Subsidies & Self-supply coefficient & Delay & Promotion factor & Population \\
\hline 1 & 1000 & 1,3 & 1 & 0,8 & $2 \mathrm{M}$ \\
\hline 2 & 3000 & 1,3 & 1 & 0,8 & $2 \mathrm{M}$ \\
\hline 3 & 1000 & 1,2 & 1 & 0,8 & $2 \mathrm{M}$ \\
\hline 4 & 2000 & 1,2 & 1 & 0,8 & $2 \mathrm{M}$ \\
\hline 5 & 2000 & 1,2 & 36 & 0,8 & $2 \mathrm{M}$ \\
\hline 6 & 2000 & 1,2 & 12 & 1 & $2 \mathrm{M}$ \\
\hline 7 & 2000 & 1,2 & 12 & 1 & $2.05 \mathrm{M}$ \\
\hline 8 & 2000 & 1,2 & 12 & 1 & $2.1 \mathrm{M}$ \\
\hline
\end{tabular}

Table 1. Values for particular scenarios considering amount of subsidies, self-supply coefficient, delay which represents to what proportion self-supply of organic farms should be considered.
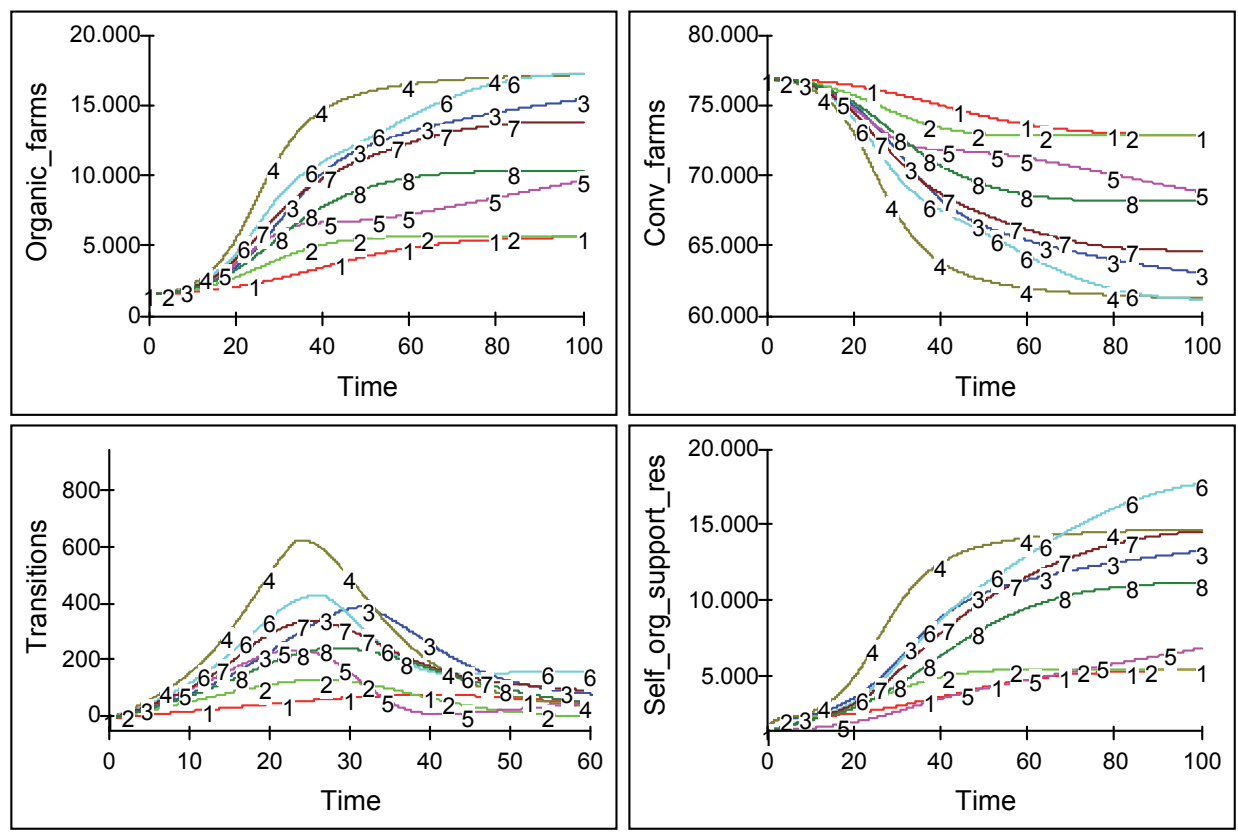

Fig. 5. Example of seven performed scenarios showing dynamics of Eco farms, Conventional farms, Transitions and Self-organizing support resources

As the mean of concept validation the results of agent-based model are shown in the following section. Tab. 2. shows list of parameter values for Agent Based Model for four different scenarios which are performed as the demonstration of how future Agent Based Model should be implemented.

Figure 6 show the results of first simulation scenario SCA1. At the beginning the transition is started with low gradient until, on account of promotion, the gradient increases as well as 
number of agents. Informal information contributes to more intensive conversion until the proportion of conventional farms is low and informal communication loses its power. As one could observe, the farms that are unchanged are on the outskirt of the system due to remoteness and lover intensity of communication with other farms. Such farms are consequently not given the same amount of informal promotion.

\begin{tabular}{|l|l|l|l|l|}
\hline Scenario & No. of farms & Effect of support & Transition factor & No. of contact \\
\hline SCA1 & 2000 & 0.011 & 0.015 & 125 \\
\hline SCA2 & 2000 & 0.1 & 0.005 & 3 \\
\hline SCA3 & 2000 & 0.05 & 0.025 & 180 \\
\hline SCA4 & 2000 & 0.01 & 0.015 & 300 \\
\hline
\end{tabular}

Table 2. List of parameter values for Agent Based Model; four different scenarios

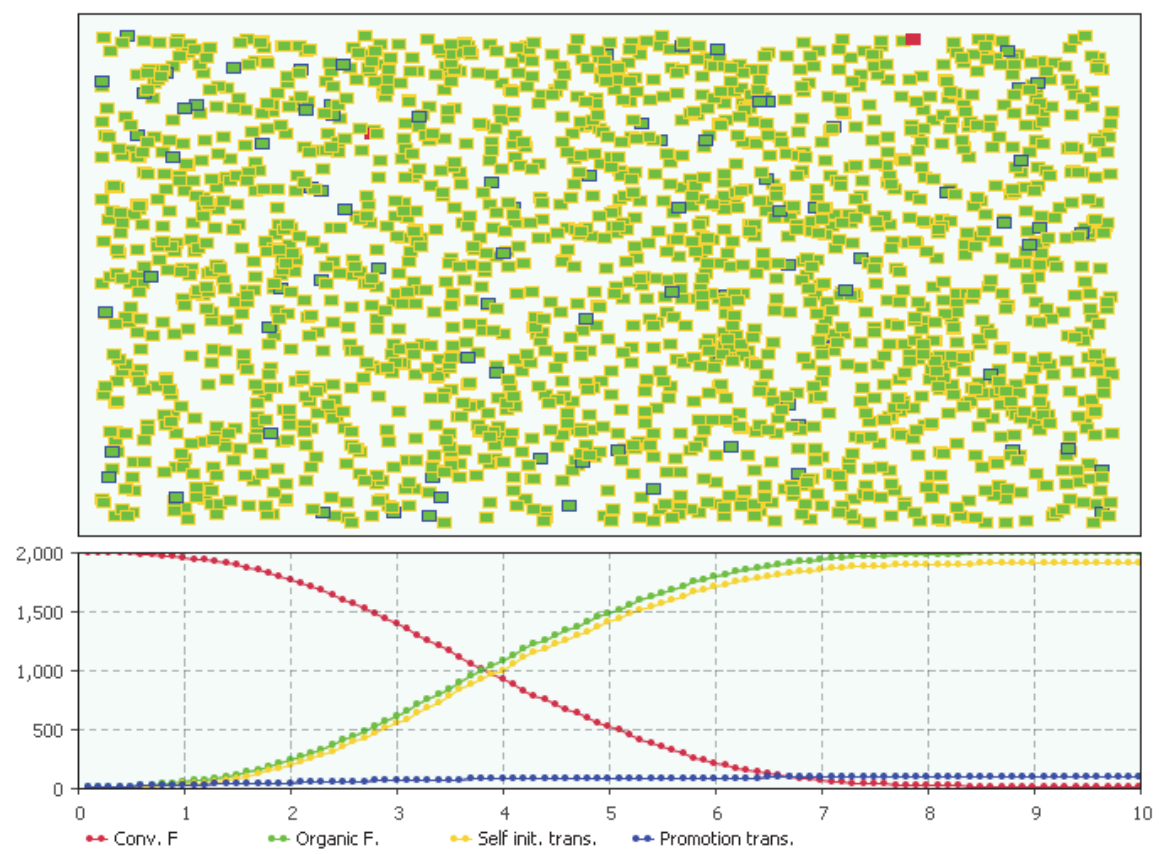

Fig. 6. Results of SC1, ABM

Figure 7 shows second scenario SCA2, where informal information flows are considered, here it is put to minimum. Increase of the model is almost linear; here the promotion of organic farming dominates in its influence. Here the importance of informal communication could be observed as well as impact of certain promotion actions, which is tied to particular number of organic farms. The proper influence of promotion is also confirmed. In the real world, such situation would occur in the case of very isolated farms, which have no proper contacts with other farms and limited access to support resources despite the fact, that the support level might be high. 


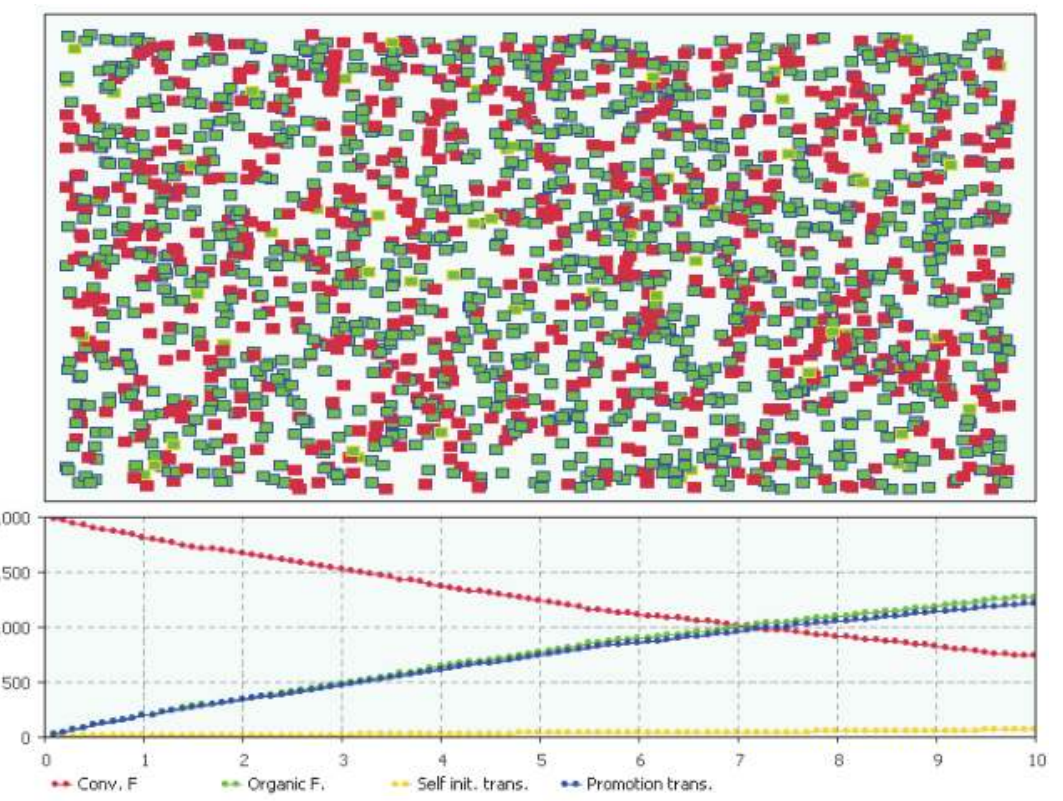

Fig. 7. Results of $S C 2, A B M$
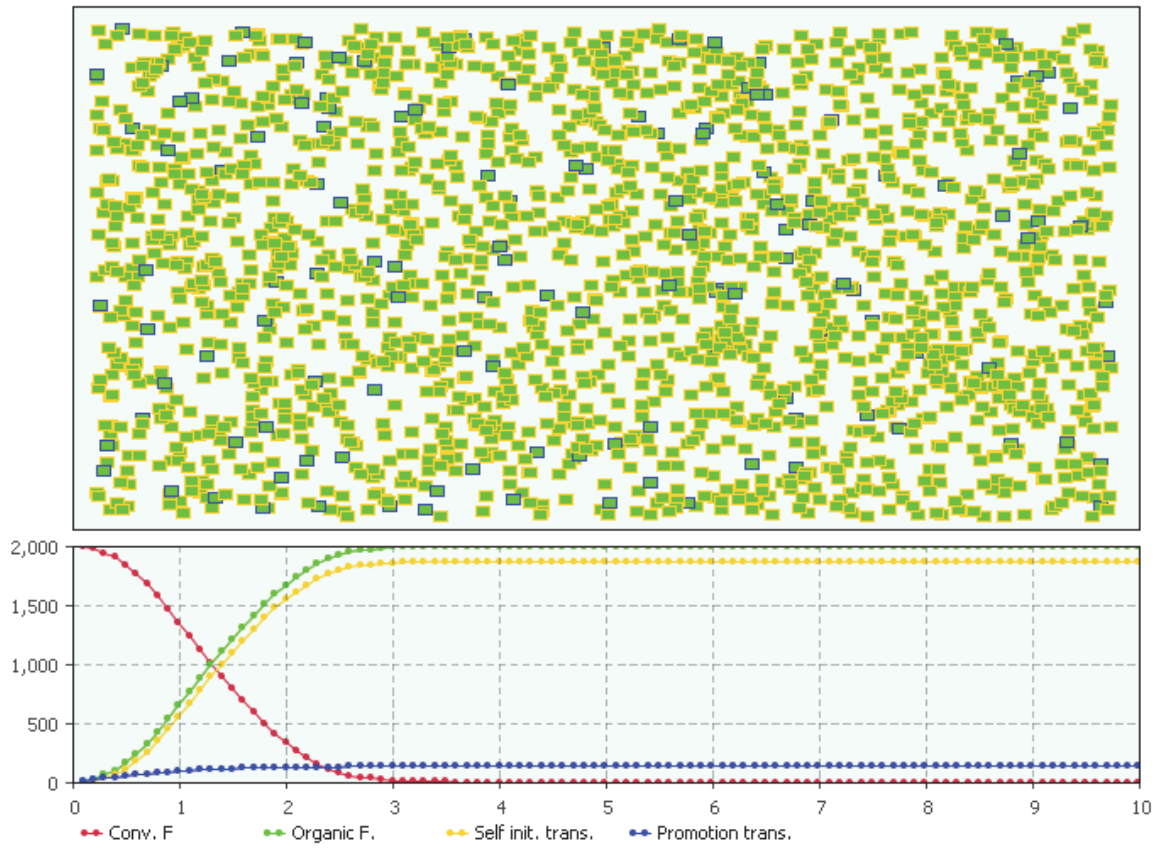

Fig. 8. Results of SC3, ABM 
Figure 8 shows third scenario SCA3, here the successfulness of promotion is lowered to minimum. On the contrary, the level of communication and transition intensity is increased as the consequence of communication i.e. promotion. As one could observe, after the initial starting time, significant increase in transition occur. One could conclude, that promotion »infects « few initial agents, which, due to the high level of communication contribute to the explosion of transitions. In the real situation this would mean, that the agents have low level of susceptibility for promotion however, they are strongly interconnected and demonstrate large level of interpersonal trust.

Figure 9 shows the fourth simulation scenario SCA4, where the key role is played by the communication between agents. The level of the communication is increased on the highest value. The parameters of promotion and the intensity of transition are lower than in the third scenario. However, the transition is exceptionally fast. One could observe, that several agents become isolated, those, who have less intensive contacts. In the real world, such situation would occur if the cooperation among agents (farms) would be very strong with strong contacts. This could be achieved via internet and other means of $\mathrm{e}$-communication, personal contacts etc. Here the technology as well as support action in the field of communication should be considered.

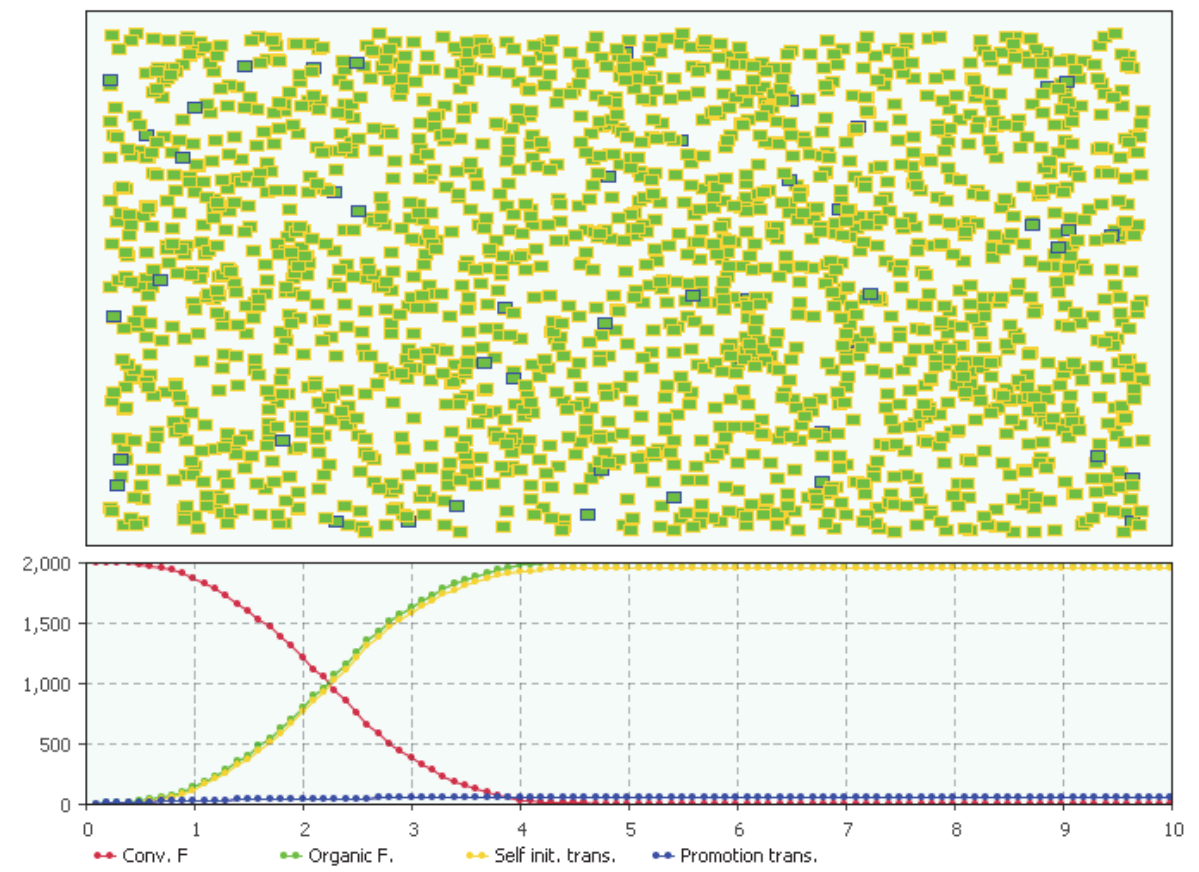

Fig. 9. Results of SC4, ABM

\section{Discussion}

Promotion factor represents the policy to promote organic farming and self-organizational resources. That would mean the development of organic-farming marketing, production 
etc., which would contribute to better demand. This value is set to 0.8 initially which means, that each new organic farm rises the resources (not only financial) for 0.8 additional organic farm by adding, e.g. to the better development of the organic marketing and prodution. The delay represents the number of months in order to spread the effect of the additional support resources in the system. Initially we consider, that this delay is short, in our case 1 month. "1" marks the response of first scenario, SC1. Self-supply coefficient represent the proportion to which the country should be self content regarding the food supply. This factor determines the food demand. 1.3 would mean, that the desired food production shoud be $30 \%$ higher of normal production. The coefficient of self-supply determines the demand which also depend on the Whole production of the agriculutral sector. Here it is important, that in the case of higher prices, the food production capacity would play a key role and influence the possible negative transitions (back to conventional farming). Population is considered as 2 million which determines the food demand. If one compares it to the scenario " 2 " where the subsidies are rised to 3000 the more intensive transitions are observed. However, the observed number of organic farms is far from desired meaning, that the subsidies by themselves would probabbly not be enough. In the scenario SC3, the impact of decreasing self-supply coefficient is considered as well as decrease in subsidies. If one decreases Self-supply coefficient, the demand/supply delay ratio would be better, influencing on the better demend for organic farming products. This would in turn compensate the lower Subsidies and provide the highest conversion so far. In scenario SC4 the subsidies are rised to 2000 which gives the best results regarding the response of the system and the limit value of the organic farms, which is approximately 17,000 . This would mean, that the right political choice would be, to increase demand for the organic farming products by lowering the self-supply and provide larger amount of subsidies. However, this could be risky in the condition of higher food prices. SC5 considers higher delay at the establishement of the self-supporting resources, which is set to 36 months. This is more realistic since the establishment of self-supporting resources takes some time. The consequence is, that the rise in the number of farms is much slower. This would mean, that it is very important, to quickly establish self-support resources for organic farming if we want to achieve fast transitions. SC6 shows the impact of lowering the delay in establishing self-support resources. Here the delay is put to the 12 months giving much better response and achieving the limit value of the organic farms, which is approximately 17,000. SC7 shows the impact of larger food demand in the case that the population would increase. This would have for the consequence larger food demand and rise in prices. It such situation, the transition would be slower and less farmers would choose to switch to the organic farming due to higher food prices. SC8 shows even worse situation if the population would have an additional increase meaning, that the demand for food would be even higher. In that case, the transition to organic farming would be even slower. One of the important questions is "How could the subsidies be replaced? « As the model shows, the main leverage is the organic farming promotion and market development. In this manner, the self-supporting resources are established which further promote the transition to the organic farming. This is the counterpart of direct subsidies which should be converted to the actions that support self organization component in the system. The presented combined methodological framework (SD) for the analysis of development of organic farming could provide additional information support to agricultural policy makers, bring additional clarity to the decision, and could therefore play an important role in further development of organic farming, in particular as assistance and advisory in policy planning. 


\section{Conclusion}

In this paper an attempt was made to employ system dynamics model in order to simulate the development of organic agriculture. The presented SD model enables simulation of different policies and this kind of model is comprehensible to a wide range of users in the decision making process.

After performing several simulation scenarios the following findings could be abstracted:

- Conversion to the organic farming relies on subsidies which provide the main source of conversion from conventional farming to organic farming.

- Subsidies are not the only driving force in the system; even more important are other activities that promote organic farming.

- Subsidies could not be provided in sufficient amount in order to complete conversion from the conventional to organic farming.

- Feasible strategy to achieve complete conversion should consider reinforcing feedback loop between resources, number of organic farms and supportive actions which are bounded to the number of organic farms.

- Current output parameter i.e. number of organic farms, is caught in an unwanted equilibrium value due to the domination of balancing feedback loops in the system.

- Important factor is self-organization of the organic farming environment which includes market development and general public awareness.

- Due to the large systemic delays in the system the anticipative value of the system control plays an important part.

- Important factor that influences the transitions to the organic farming is demand on the market which is largely driven by the politics and the self-supply principle.

- The agent based model shows that it is possible to build an agent-based model which would enable to monitor each particular farm and its transition. The tool AnyLogic has been identified as the proper tool for such modeling task.

Further strategic actions should consider the dynamic response of the system and the feasibility of stated system target values. Consideration of the interaction of four main feedback loops indicated in the system which determines the system performance provides the means for proper control strategy definition.

The presented combined methodological framework (SD) for the analysis of development of organic farming could provide additional information support to agricultural policy makers, bring additional clarity to the decision, and could therefore play an important role in further development of organic farming, in particular as assistance and advisory in policy planning. Further research is needed in the field of SD modeling in order to properly evaluate the applicability of the proposed model. Especially the market development of organic food should be additionally considered as proposed by Rozman et al., (2008). The SD model should be further verified and correspondingly improved. The agent-based model should be developed which would enable precise monitoring of each particular farm. The model structure and its results should be evaluated by relevant expert group.

\section{References}

Akinwumi, A.A; Mbila, D.; Nkamleub, G.B. \& Endamana, D. (2000). Econometric analysis of the determinants of adoption of alley farming by farmers in the forest zone of southwest Cameroon Agriculture, Ecosystems and Environment, Vol. 80, pp. 255-265 
Bockermann, A.; Meyer, B.; Omannc, I. \& Spangenberg, J.H. (2005). Modelling sustainability Comparing an econometric (PANTA RHEI) and a systems dynamics model (SuE), Journal of Policy Modeling, Vol. 27, pp. 189-210

Boorsma, A. (1990). Possibilities for Arable Farms in the Dutch Peat Soil District. PhD thesis, Rijks Universiteit Groningen, Groningen (Dutch).

Bontkes, T.S. \& Van Keulen, H. (2003). Modelling the dynamics of agricultural development at farm and regional level, Agricultural Systems, Vol. 76, No.1, pp. 379-396

Dubois D., Resconi G. (1992); Hyperincurisvity - a new mathematical theory, $1^{\text {st }}$ ed. Presses Universitaires de Liège.

Borschev, A. \& Filippov, A. (2004). From System Dynamics and Discrete Event to Practical Agent Based Modeling: Reasons, Techniques, Tools. The 22nd International Conference of the System Dynamics Society, July 25 - 29, 2004, Oxford, England.

Elshorbagy, A.; Jutla, A. \& Barbour, L. (2005). System dynamics approach to assess the sustainability of reclamation of disturbed watersheds, Can. J. Civil Eng., Vol. 32, No.1, pp. 144-158

Forrester, J.W. (1961). Industrial Dynamics, MIT Press, Cambridge, MA, pp. 464

Hong S.H. (2008). Forest landscape models: Definitions, characterization, and classification, Forest Ecology and Management, Vol. 254, No. 3

(http:/ / www.sciencedirect.com/science/article/B6T6X-4R16JMP3/2/44b9afbe4381a00ac6d7616d18001896)

Ivančič, A.; Turk, J.; Rozman, Č. \& Šiško, M. (2003). Agriculture in the Slovenia transition economy: The preservation of genetic diversity of plants and ethical consequences, Journal of Agricultural and Environmental Ethics, Vol. 16, pp. 337-365

Kaufmann P.; Stagl, S. \& Franks, D.W. (2009). Simulating the diffusion of organic farming practices in two New EU Member States, Ecological Economics, Vol. 68, pp. 25802593

Kljajić M. (1998). Modeling and Understanding the Complex System Within Cybernetics. Ramaekers M. J. (Ed.), 15th International Congress on Cybernetics. Association International de Cybernetique. Namur, pp. 864-869

Kljajić, M.; Bernik, I.; \& Škraba, A. (2000). Simulation Approach to Decision Assessment in Enterprises, Simulation, Vol. 75, No. 4, pp. 199-210

Kljajić, M. (2001). Contribution to the meaning and understanding of anticipatory systems. V: DUBOIS, Daniel M. (ur.). Computing anticipatory systems, (AIP conference proceedings, 573). Melville (New York): American Institute of Physics, 2001, pp. 400-411

Kljajić, M.; Cav, L. \& Škraba, A. (2002). System Dynamics Model Development of The Canary Islands for Supporting Strategic Public Decisions. Proc. of the 20th International Conference of the System Dynamics Society; The System Dynamics Society, Palermo, Italy, pp.16

Kljajić, M.; Cav, L.; Škraba, A. \& Peternel, J. (2003). Simulation Model of the Canary Islands for Public Decision Support - Preliminary Results. Proc. of the 20 th International Conference of the System Dynamics Society; The System Dynamics Society, Albany, NY

Kljajić, M.; Škraba, A.; Kofjač, D. \& Bren, M. (2005). Discrete Cobweb Model Dynamics with Anticipative Structure, WSEAS Transactions on Systems, Vol. 4, No. 5 
Korthals, M. (2008). Ethical Rooms for Maneuver and Their Prospects Vis-à-vis the Current Ethical Food Policies in Europe, Journal of Agricultural and Environmental Ethics, Vol. 21, No. 3

Majcen M.H. \& Jurcan S. (Eds.) (2006). Action Organic Farming Development Plan in Slovenia to Year 2015 (ANEK), Government of Republic of Slovenia.

Majkovič, D.; Borec, A.; Rozman, Č.; Turk, J. \& Pažek, K. (2005). Multifunctional concept of agriculture: Just an idea or the real case scenario? Društvena istraživanja, Vol. 14, No. 3, pp. 579-596

Munitič, A. \& Trosić, Z. (1997). System dynamics continuous modelling of the ecological subsystem of the 'Kastela Bay', Simulation Practice and Theory, Vol. 5, No. 7-8, Selected papers of the 5th European Simulation Congress, 15 October 1997, pp. 701717, ISSN 0928-4869, DOI: 10.1016/S0928-4869(97)00017-7.

(http://www.sciencedirect.com/science/article/B6V19-3SP2RCD-

9/2/f2a7df3b95f6ac8c2f6b4a62edf0c018)

Pažek, K.; Rozman, Č.; Borec, A., Turk, J., Majkovič, D., Bavec, M. \& Bavec, F. (2006). The use of multi criteria models for decision support on organic farms. Biol. agric. hortic., Vol. 24, no.1, pp. 73-89.

Rozman, Č.; Škraba, A.; Kljajić, M.; Pažek, K.; Bavec, M. \& Bavec, F. (2008). The Development of organic agriculture model - a system dynamics approach to support decision making processes. In Symposium on Engineering and Management of IT-based organizational system (pp. 39-44). Baden-Baden, Germany: The international institute for advances studies in system research and cybernetics.

Rozman, Č.; Škraba, A.; Kljajić, M.; Pažek, K.; Bavec, M. \& Bavec, F. (2007a). The system dynamics model for development of organic agriculture. In D. M. Dubois (Ed.), Eighth International Conference on Computing Anticipatory Systems, HEC-ULg. Liege, Belgium: CASYS'07, in press.

Rozman, Č.; Škraba, A.; Pažek, K. \& Kljajić, M. (2010). The System dynamics model for strategic planning of organic farming development. V: KLJAJIĆ, Miroljub (ur.), LASKER, George Eric (ur.). Advances in simulation-based decision support : [papers presented the 22nd International Conference on Systems Research, Informatics and Cybernetics held August 2-6, 2010 in Baden-Baden, Germany]. Tecumseln (Canada): The International Institute for Advanced Studies in Systems Research and Cybernetics, pp. 31-35.

Rozman, Č. \& Pažek, K. (2005). Application of computer supported multi-criteria decision models in agriculture. Agric. conspec. sci., Vol. 70, No. 4, pp. 127-134.

Rozman, Č.; Škraba, A.; Kljajić, M.; Pažek, K.; Bavec, M. \& Bavec, F. (2007). The system dynamics model for development of organic agriculture. In: DUBOIS, Daniel M. (ur.). Eighth International Conference on Computing Anticipatory Systems, HECULg, Liege, Belgium, CASYS'07 : abstract book, (Casys).

Shi, T. \& Gill, R. (2005). Developing effective policies for the sustainable development of ecological agriculture in China: the case study of Jinshan County with a systems dynamics model, Ecological Economics, Vol. 53, No. 2, pp. 23-246

Shen, Q.; Chen, Q.; Tang, Bo-sin.; Yeung, S.; Hu, Y. \& Cheung, G. (2009). A system dynamics model for the sustainable land use planning and development, Habitat International, Vol. 33, No. 1, pp. 15-25. 
Šraba, A.; Rozman, Č., Klajić, M.; Pažek, K., Bavec, M., Bavec, F. \& Kofljač, D. (2008). Strategy for organic farming model development. V: Dangefrield, B.C. (ed.). Proceedings of the 26th International Conference [of] the System Dynamics Society, Athens, Greece, July 20 - July 24, 2008. Albany (New York): The System Dynamics Society, cop, pp. 104-105

Weber, G.; Smith, J.; \& Manyong, M.V. (1996). System dynamics and the definition of research domains for the northern Guinea savanna of West Africa, Agriculture, Ecosystems \& Environment, Vol. 57, No. 2-3, pp. 133-148 


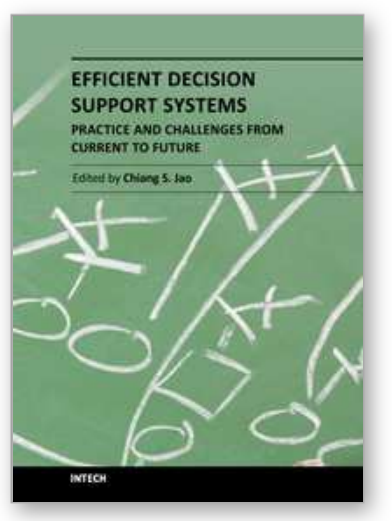

\section{Efficient Decision Support Systems - Practice and Challenges From Current to Future}

Edited by Prof. Chiang Jao

ISBN 978-953-307-326-2

Hard cover, 542 pages

Publisher InTech

Published online 09, September, 2011

Published in print edition September, 2011

This series is directed to diverse managerial professionals who are leading the transformation of individual domains by using expert information and domain knowledge to drive decision support systems (DSSs). The series offers a broad range of subjects addressed in specific areas such as health care, business management, banking, agriculture, environmental improvement, natural resource and spatial management, aviation administration, and hybrid applications of information technology aimed to interdisciplinary issues. This book series is composed of three volumes: Volume 1 consists of general concepts and methodology of DSSs; Volume 2 consists of applications of DSSs in the biomedical domain; Volume 3 consists of hybrid applications of DSSs in multidisciplinary domains. The book is shaped upon decision support strategies in the new infrastructure that assists the readers in full use of the creative technology to manipulate input data and to transform information into useful decisions for decision makers.

\section{How to reference}

In order to correctly reference this scholarly work, feel free to copy and paste the following:

Crtomir Rozman, Andrej Skraba, Karmen Pažek, Miroljub Kljajić, Martina Bavec and Franci Bavec (2011). Determination of Effective Policies for Ecological Agriculture Development with System Dynamics and Agent Based Models - Case Study in Slovenia, Efficient Decision Support Systems - Practice and Challenges From Current to Future, Prof. Chiang Jao (Ed.), ISBN: 978-953-307-326-2, InTech, Available from: http://www.intechopen.com/books/efficient-decision-support-systems-practice-and-challenges-from-current-tofuture/determination-of-effective-policies-for-ecological-agriculture-development-with-system-dynamics-and-

\section{INTECH}

open science | open minds

\section{InTech Europe}

University Campus STeP Ri

Slavka Krautzeka 83/A

51000 Rijeka, Croatia

Phone: +385 (51) 770447

Fax: +385 (51) 686166

www.intechopen.com

\section{InTech China}

Unit 405, Office Block, Hotel Equatorial Shanghai

No.65, Yan An Road (West), Shanghai, 200040, China 中国上海市延安西路65号上海国际贵都大饭店办公楼 405 单元

Phone: +86-21-62489820

Fax: +86-21-62489821 
(C) 2011 The Author(s). Licensee IntechOpen. This chapter is distributed under the terms of the Creative Commons Attribution-NonCommercialShareAlike-3.0 License, which permits use, distribution and reproduction for non-commercial purposes, provided the original is properly cited and derivative works building on this content are distributed under the same license. 